\title{
Occurrence and trends in ski injuries in Norway
}

\author{
Øydis Ueland, Branko Kopjar
}

\begin{abstract}
Objectives-To provide an overview of ski injuries in Norway and to describe the changes between 1990 and 1996.

Methods-All ski injuries (7966) treated at four hospitals providing health care to a defined population of about $11 \%$ of the Norwegian population were registered prospectively from 1990 to 1996 . For this study, 6462 injuries sustained in cross country skiing, downhill skiing, telemark skiing, and snowboarding were selected for further analysis.

Results-The relative distribution of ski injuries by type of skiing changed significantly from 1990 to 1996 ( $p<0.001)$. Injuries from snowboarding showed the highest relative increase, and those sustained during downhill skiing showed a decline. The proportion of fractures in all types of skiing increased during the study period $(p=0.001)$. The proportion of injuries to knee/lower leg decreased and the proportion to the forearm/wrist/hand increased during the study period $(p=0.03)$. The mean age of the injured skiers differed significantly among the different types of skiing activity $(p<0.001)$ : cross country skiers were the oldest followed by telemark skiers, downhill skiers, and snowboarders.

Conclusions-Ski injury surveillance results in early detection of changes in temporal injury trends, allowing timely adjustment of injury prevention strategies. Injuries from snowboarding are on the increase in Norway, warranting more effective injury prevention measures. (Br F Sports Med 1998;32:299-303)
\end{abstract}

Keywords: ski injuries; temporal changes; descriptive studies; injury incidence

Skiing is among the most popular sports and recreational activities in Norway. ${ }^{1}$ It is also a common cause of medically treated sports injuries in the country, second only to injuries sustained in ball sports. ${ }^{23}$ It is a significant source of morbidity among the population and occasionally the cause of fatal injuries. This makes it an important target for the implementation of risk reduction measures.

Several different types of skiing are practised in Norway. Cross country, the most popular, is performed by people of all ages. ${ }^{4}$ It can be carried out anywhere as long as there is a sufficient depth of snow. Furthermore, cross country skiing is becoming increasingly popular in many non-Nordic countries. ${ }^{5}$ Data from nationwide omnibus surveys suggest that between 40 and $50 \%$ of the population cross country ski, and this has not changed over a long period. ${ }^{6}$ Other frequently pursued skiing activities in Norway are downhill and telemark skiing and snowboarding. Downhill skiing requires prepared slopes and ski lifts. The main feature of telemark skiing is a "free heel", turning technique practised on slopes of various gradients. Telemark skiing can be performed both on prepared slopes and in the back country. The equipment for telemark skiing enables the skier to glide and climb as well as descend. Telemark skis are less flexible and boots provide more support for the foot than those used by cross country skiers. The bindings used for telemark skiing leave the skier's heel free to be lifted. In snowboarding, the performer is anchored with both feet to the board. Snowboarders do not use staves. Snowboarding is usually performed on prepared slopes.

Outside of Nordic countries, downhill is the most popular type of skiing, and causes $85 \%$ of ski injuries. ${ }^{7}$ In Norway, cross country skiing produces a similar frequency of injury to downhill skiing. ${ }^{2}$ The popularity of cross country skiing is increasing in many other countries. $^{5} 78$

Only a few studies have analysed injuries sustained in cross country skiing. ${ }^{5}$ Even less attention has been paid to injuries from snowboarding and telemark skiing. ${ }^{9-11}$

This study analyses temporal changes in ski injuries in Norway from 1990 to 1996 by type of skiing. It is hypothesised that the emergence of new types of skiing activity, such as snowboarding, will influence the occurrence and characteristics of ski injuries.

\section{Materials and methods}

DATA SOURCE

Cases of ski injury were identified through the Norwegian National Injury Register (NNIR). ${ }^{12}$ The NNIR prospectively collects data on injuries treated at four hospitals and their emergency wards situated in four towns in Norway (Drammen, Stavanger, Trondheim, Harstad). These medical facilities provide emergency care to a defined population representing about $11 \%$ of the total Norwegian population. Information collected by the NNIR includes the circumstances of the injury and the medical presentation, but information on the outcome is not routinely collected.

\section{CASE SELECTION}

Initially, all cases of ski injury registered with the NNIR from 1990 to 1996 were included in the study, 7966 in total. Of these, 1504 were excluded for the following reasons: 853 lacked information about the type of skiing activity; 599 were injuries sustained in ski jumping, freestyle, towing, and miniskiing activities; 52
Accepted for publication 11 June 1998 
Table 1 Distribution of ski injuries by skiing activity and year of injury

\begin{tabular}{|c|c|c|c|c|c|c|c|c|}
\hline \multirow[b]{2}{*}{ Skiing activity* } & \multicolumn{7}{|l|}{ Year } & \multirow[b]{2}{*}{ Total } \\
\hline & 1990 & 1991 & 1992 & 1993 & 1994 & 1995 & 1996 & \\
\hline Cross country skiing & 201 & 341 & 383 & 590 & 510 & 435 & 493 & 2953 \\
\hline Downhill skiing & 381 & 388 & 360 & 482 & 367 & 357 & 262 & 2597 \\
\hline Telemark skiing & 37 & 39 & 65 & 60 & 67 & 73 & 65 & 406 \\
\hline Snowboarding & 27 & 28 & 41 & 67 & 65 & 106 & 172 & 506 \\
\hline Total & 646 & 796 & 849 & 1199 & 1009 & 971 & 992 & 6462 \\
\hline
\end{tabular}

$\star \chi^{2}=356, \mathrm{df}=18, \mathrm{p}<0.001$.

were injuries related to the use of ski lifts and ski equipment such as staves and bindings. The proportion of cases in which the type of skiing activity was not known was stable over the study period. The remaining 6462 injuries were included in the analysis. These cases represented four types of skiing activity: cross country skiing, downhill skiing, telemark skiing, and snowboarding. About $80 \%$ of the patients were local residents, $18 \%$ were other Norwegian residents, and $2 \%$ were foreigners. The following information was obtained for each case: type of skiing activity, gender, age, treatment disposition, Abbreviated Injury Severity (AIS) score, ${ }^{13}$ and diagnosis.

\section{STATISTICAL ANALYSIS}

The $\chi^{2}$ test was used to calculate the statistical significance of the changes in the relative distributions of injuries according to type of skiing activity over the study period. It was further used to calculate differences in the relative distributions by gender, treatment disposition, localisation of injury, and injury diagnosis during the study period and within the types of skiing activity. Kruskal-Wallis analysis of variance was used to determine the significance of the changes in injury severity and age during the study period, and to test differences in the age distribution of the injured skiers participating in different skiing activities.

\section{Results}

TEMPORAL TRENDS IN SKI INJURIES FROM 1990 TO 1996

The distribution of ski injuries according to type of skiing activity showed significant temporal changes from 1990 to 1996 $(p<0.001)$. The annual incidence of ski injuries increased from 1990 to 1996, with the peak in 1993 (table 1). Snowboard injuries showed the highest relative increase in incidence.
Injury severity did not show any significant changes during the study period. The proportion of injuries requiring hospitalisation was highest in $1994(18.2 \%)$ and lowest in 1991 and 1996 (13.1 and $13.7 \%$ respectively, $\mathrm{p}=$ $0.02)$. The relative distribution of injuries by diagnosis changed over the study period ( $\mathrm{p}=$ 0.001 ). The proportion of fractures increased from $26.6 \%$ in 1990 to $30.5 \%$ in 1996 ( $p=$ $0.001)$. Also, the relative distribution of injuries by location of injury changed during the study period ( $p=0.03$ ). The proportion of injuries to knee/lower leg decreased from $29.3 \%$ in 1990 to $20.4 \%$ in $1996(\mathrm{p}=0.03)$. At the same time the proportion of injuries to forearm/wrist/ hand increased from $13.8 \%$ in 1990 to $18.4 \%$ in 1996.

A segregated analysis by type of skiing activity disclosed no significant temporal changes in severity of injury, treatment disposition, gender, or age for different types of skiing. The proportion of all injuries that were fractures increased for cross country skiers $(p=0.006)$. Snowboard injuries showed a tendency towards a relative increase in forearm/wrist/hand injuries and a corresponding decline in knee/ lower leg injuries during the study period $(p<0.001)$.

\section{CHARACTERISTICS OF THE INJURED SKIERS BY} TYPE OF SKIING ACTIVITY

There were statistically significant differences in age of the injured skiers by type of skiing activity. Those injured in downhill skiing, telemark skiing, and snowboarding were younger than those injured while cross country skiing $(p<0.001)$. The mean (SD) age of the injured skiers was 36 (19) for cross country skiers, 22 (12) for downhill skiers, 24 (7) for telemark skiers, and 18 (6) for snowboarders.

Most $(61 \%)$ ski injuries occurred in men $(\mathrm{p}<0.001)$. They were over-represented among

Table 2 Distribution of injury severity (AIS) and hospitalisation rate for each skiing activity. Injuries registered 1990-1996. Percentages describe the distribution within each skiing activity for each characteristic

\begin{tabular}{|c|c|c|c|c|c|c|c|c|}
\hline \multirow[b]{3}{*}{ Characteristics } & \multicolumn{8}{|c|}{ Skïng activity } \\
\hline & \multicolumn{2}{|c|}{ Cross country } & \multicolumn{2}{|c|}{ Downhill } & \multicolumn{2}{|c|}{ Telemark } & \multicolumn{2}{|c|}{ Snowboarding } \\
\hline & $n$ & $\%$ & $n$ & $\%$ & $n$ & $\%$ & $n$ & $\%$ \\
\hline \multicolumn{9}{|l|}{ Injury severity* } \\
\hline Low (AIS 1) & 1854 & 63.0 & 1619 & 62.7 & 308 & 75.9 & 293 & 57.9 \\
\hline Moderate (AIS 2) & 823 & 28.0 & 722 & 28.0 & 72 & 17.7 & 170 & 33.6 \\
\hline Severe (AIS 3-5) & 265 & 9.0 & 242 & 9.4 & 26 & 6.4 & 42 & 8.3 \\
\hline Total & 2942 & 100.0 & 2583 & 100.0 & 406 & 100.0 & 506 & 100.0 \\
\hline \multicolumn{9}{|l|}{ Hospitalisation $\dagger$} \\
\hline Yes & 413 & 14.0 & 477 & 18.4 & 47 & 11.6 & 53 & 10.5 \\
\hline No & 2540 & 86.0 & 2119 & 81.6 & 359 & 88.4 & 452 & 89.5 \\
\hline Total & 2953 & 100 & 1596 & 100 & 406 & 100 & 505 & 100 \\
\hline
\end{tabular}

$\star \chi^{2}=30.8, \mathrm{df}=3, \mathrm{p}<0.001$

$+\chi^{2}=36, \mathrm{df}=3, \mathrm{p}<0.001$. 
Table 3 Distribution of ski injury characteristics by skïng activity. Injuries registered 1990-1996. Percentages describe the distribution within each skiing activity for each characteristic

\begin{tabular}{|c|c|c|c|c|c|c|c|c|}
\hline \multirow[b]{3}{*}{ Injury } & \multicolumn{8}{|c|}{ Skïng activity } \\
\hline & \multicolumn{2}{|c|}{ Cross country } & \multicolumn{2}{|c|}{ Downhill } & \multicolumn{2}{|c|}{ Telemark } & \multicolumn{2}{|c|}{ Snowboarding } \\
\hline & $n$ & $\%$ & $n$ & $\%$ & $n$ & $\%$ & $n$ & $\%$ \\
\hline Concussion, head/face & 32 & 1.1 & 91 & 3.5 & 6 & 1.5 & 7 & 1.4 \\
\hline Laceration, head/face & 55 & 1.9 & 61 & 2.4 & 10 & 2.5 & 9 & 1.8 \\
\hline Contusion, head/face & 35 & 1.2 & 30 & 1.2 & 1 & 0.2 & 8 & 1.6 \\
\hline Fracture, head/face & 3 & 0.1 & 14 & 0.5 & 2 & 0.5 & 1 & 0.2 \\
\hline Fracture, shoulder/upper arm & 116 & 4.0 & 84 & 3.3 & 5 & 1.2 & 20 & 4.0 \\
\hline Contusion, shoulder/upper arm & 84 & 2.9 & 50 & 1.9 & 17 & 4.2 & 6 & 1.2 \\
\hline Sprain, shoulder/upper arm & 94 & 3.2 & 47 & 1.8 & 10 & 2.5 & 5 & 1.0 \\
\hline Dislocation, shoulder/upper arm & 58 & 2.0 & 40 & 1.6 & 5 & 1.2 & 5 & 1.0 \\
\hline Fracture, lower arm/wrist/hand & 242 & 8.3 & 202 & 7.8 & 12 & 3.0 & 107 & 21.2 \\
\hline Sprain, lower arm/wrist/hand & 140 & 4.8 & 99 & 3.8 & 22 & 5.4 & 58 & 11.5 \\
\hline Contusion, lower $\mathrm{arm} / \mathrm{wrist} / \mathrm{hand}$ & 41 & 1.4 & 46 & 1.8 & 2 & 1.5 & 16 & 3.2 \\
\hline Sprain, finger & 131 & 4.5 & 157 & 6.1 & 34 & 8.4 & 8 & 1.6 \\
\hline Fracture, finger & 82 & 2.8 & 88 & 3.4 & 13 & 3.2 & 5 & 1.0 \\
\hline Contusion, finger & 21 & 1.4 & 29 & 1.1 & 5 & 1.2 & 3 & 0.6 \\
\hline Fracture, torso & 174 & 5.9 & 110 & 4.3 & 10 & 2.5 & 34 & 6.7 \\
\hline Contusion, torso & 79 & 2.7 & 85 & 3.3 & 10 & 2.5 & 24 & 4.8 \\
\hline Sprain, knee/lower leg & 471 & 16.1 & 458 & 17.8 & 73 & 18.1 & 47 & 9.3 \\
\hline Fracture, knee/lower leg & 60 & 2.0 & 157 & 6.1 & 8 & 2.0 & 9 & 1.8 \\
\hline Contusion, knee/lower leg & 56 & 1.9 & 94 & 3.6 & 12 & 4.2 & 14 & 2.8 \\
\hline Sprain, ankle/foot & 266 & 9.1 & 127 & 4.9 & 61 & 15.1 & 40 & 7.9 \\
\hline Fracture, ankle/foot & 161 & 5.5 & 49 & 1.9 & 33 & 8.2 & 15 & 3.0 \\
\hline Multiple injuries & 44 & 1.5 & 64 & 2.5 & 3 & 0.7 & 5 & 1.0 \\
\hline Other & 288 & 16.6 & 395 & 15.3 & 50 & 12.4 & 59 & 11.7 \\
\hline Total & 2933 & 101.0 & 2577 & 99.0 & 404 & 102.0 & 505 & 100.0 \\
\hline
\end{tabular}

injured downhill skiers (65\%), telemark skiers $(70 \%)$, and snowboarders (81\%), and accounted for $52 \%$ of the cases of injury in cross country skiers.

Injury severity varied by type of skiing activity $(\mathrm{p}<0.001)$ (table 2$)$. The highest proportion of severe injuries came from snowboarding, followed by downhill skiing, cross country skiing, and telemark skiing. The rate of hospitalisation was highest for downhill skiers and lowest for snowboarders $(\mathrm{p}<0.001)$ (table 2).

The most common diagnoses were sprains $(40.3 \%)$, followed by fractures $(30.2 \%)$ and contusions $(15.1 \%)$. Table 3 shows the distribution of injuries by diagnosis and type of skiing.

\section{Discussion}

TEMPORAL TRENDS IN SKI INJURIES

The incidence of ski injury in the study area increased over 50\% from 1990 to 1996 . The increase varied according to the type of skiing. The highest increase in absolute number of injuries occurred for cross country skiing, and the highest relative increase was for snowboarding. As a result of these temporal changes, the clinical presentation of injuries changed over time. By the end of the study period, injuries were more severe; there was an increase in the proportion of fractures and an increase in the rate of hospitalisation.

Injury patterns follow changes in people's activities. In our study, changes in types of skiing activity were associated with changes in types and severity of injuries, and in the characteristics of injured skiers. This observation underlines the importance of continuous injury surveillance in planning and implementation of targeted preventive efforts as well as in appropriate planning of medical services.

The temporal changes in incidence and characteristics of the ski injuries observed in this study corroborate the findings of others. An increased incidence of snowboard injuries has been shown in several recent studies. ${ }^{9}{ }^{10}{ }^{14} \mathrm{~A}$
Norwegian study reported a declining trend in downhill injury incidence between 1990 and 1993. ${ }^{3}$ Two cross sectional studies described telemark skiing injuries, ${ }^{11}{ }^{15}$ but we could find no reports of temporal trends in these injuries.

The increased incidence of ski injuries over time observed in this study is probably due to greater exposure to skiing. Although we lack direct data, there are indicators of increased exposure. For example, during the study period, sales of telemark skis and snowboards showed an exponential increase. Sales statistics for cross country skis remained stable and those for alpine skis showed a decline (S Ness, Managing Director, the Norwegian Sporting Goods Association, personal communication). This correlates well with the temporal changes in number of injuries from different types of skiing. A declining trend in the incidence of downhill skiing injuries was observed in the 1970 s. ${ }^{7617}$ The decline has been attributed to improved safety of skiing equipment and skiing facilities. ${ }^{7}$ The downward temporal trend in incidence of downhill ski injuries observed in this study is probably due to reduced exposure.

Several studies have shown that a lack of experience and ability are risk factors for ski injuries. ${ }^{18-20}$ It is possible that these factors contributed to the high incidence of ski injuries observed in 1993. From 1990 to 1992 there was relatively little snow, while in 1993 snow quantities were normal. In 1994 and 1995, the amounts of snow were large. It could be hypothesised that in 1993 there were many novice skiers or skiers that lacked practice after several years with little snow, and these sustained a larger number of injuries than normal.

CHARACTERISTICS OF INJURED SKIERS

The skiers injured while downhill skiing or snowboarding were younger than those injured while cross country or telemark skiing. Other studies have found a similar age distribution of ski injuries. ${ }^{15}$ The injured skiers in the present 
study tended to be younger than those from other countries, ${ }^{8} 9111_{19}^{21-23}$ suggesting that the skiing population in Norway is younger than those in other countries. A climate that is favourable for winter sports and a cultural expectancy of an early skiing debut may account for this. ${ }^{24}$

The high proportion of knee/lower leg injuries observed in cross country skiing is of concern. Detailed analyses of the knee injuries of cross country skiers should be conducted to determine whether such skiers could benefit from changes in product design. As in downhill skiing, changes in binding construction could perhaps reduce knee injuries.

Our findings show that downhill skiers, more than other skiers, sustain complex injuries requiring hospitalisation (data not shown). The higher speed attained by these skiers before the injury event probably accounts for the higher rate of hospitalisation.

Data presented in this paper show that injuries to the ankle/foot and knee are most frequent in telemark skiing. Greater focus on the correct equipment for the different styles of telemark skiing would probably prevent some of these injuries.

The high proportion of snowboard injuries reported in this study is in accordance with the findings of others. ${ }^{914}{ }^{15}$ Snowboarding is a new and emerging sport in Norway, and many of the participants are therefore beginners. ${ }^{10}$ It has been suggested that interventions such as wearing of wrist guards and training in falling techniques may reduce injury severity. ${ }^{10}$

METHODOLOGICAL CONSIDERATIONS

It is uncertain to what extent our data are representative of the whole country. Some of the main skiing areas in Norway lie outside the injury registration catchment area for the study. This may account for the low number of injuries sustained by tourists. It is, however, unlikely that the areas studied differ from the rest of the country with respect to the implementation of new trends and sports, suggesting that the observed temporal changes are representative of the country as a whole.

As this study is based on injury data from hospitals and emergency wards, injuries that did not require medical treatment or were treated by local general practitioners are not included in the study. Thus the injury distribution reported in this study will be skewed towards higher proportions of fractures and severe injuries.

CONCLUSION

The data from this study emphasise the importance of close follow up of the development of ski injuries. Changes in the distribution of skiing injuries occur over time, reflect- ing changes in exposure to different types of skiing activity. Particular emphasis is required to prevent injuries to young skiers.

1 Dølvik JE. Sports, recreation and organisation. FAFO report no. 99. Oslo: Institute for Applied Social Sciences, 1990. (In Norwegian.)

2 Guldvog B, Thorgersen A, Ueland Ø. Accidents, violence and self-inflicted injury. Injury report. SAFH report 1/92. Oslo: National Institute of Public Health, 1992. (In Norwegian.)

3 Ytterstad B. The Harstad injury prevention study: the epidemiology of sports injuries. An 8 year study. BrF Sports Med 1996;30:64-8.

4 Ekeland A. Ski injuries and ski safety. Tidsskr Nor Leegeforen 1993;113:3671-2. (In Norwegian.)

5 Smith M, Matheson GO, Meeuwisse WH. Injuries in crosscountry skiing. A critical appraisal of the literature. Sports Med 1996;21:239-50.

6 Vorkinn M, Aas O, Kleiven J. Performance of outdoor recreation in the adult population - trends and status in 1996. ØF Report 1997/7. Lillehammer: Østlandsforskning, 1997. (In Norwegian.)

7 Ekeland A, Nordsletten L. Equipment related injuries in skiing. Recommendations. Sports Med 1994;17:283-6.

8 Shealy JE, Miller DA. A relative analysis of downhill and cross-country ski injuries. In: Mote Jr CD, Johnson RJ, eds. Skiing trauma and safety: eighth international symposium. Philadelphia: American Society for Testing and Materials, 1991;133-43.

9 Sutherland AG, Holmes JD, Myers S. Differing injury patterns in snowboarding and alpine skiing. Injury 1996;27:423-5.

10 Bladin C, McCrory P. Snowboarding injuries. An overview. Sports Med 1995;19:358-64.

11 Tuggy ML. Telemark skiing injuries. $\mathcal{F}$ Sports Med Phys Fitness 1996;36:217-22

12 Wiik J, Kopjar B, Bulajic-Kopjar M. Trends in bicyclerelated injuries in Norway, 1990-1993. Does prevention yield effects? International fournal of Consumer Safety 1996; 3:67-77.

13 Committee on Injury Scaling. The abbreviated injury scale: 1984 revision. Des Plaines, IL: American Association of Automotive Medicine, 1985.

14 Björnstig J, Björnstig U. Snowboard injuries can be prevented. Nord Med 1996;111:7-9. (In Swedish.)

15 Jørgsholm P, Bauer M, Ljung B, et al. The development of downhill skiing: snowboarding and telemark skiing give
new injury patterns. Läkartidningen 1991;88:1589-92. (In new injury

16 Soma CA, Mandelbaum BR, Watanabe DS, et al. Alpine and cross-country skiing. In: Caine DJ, Caine CG, Lindner $\mathrm{KJ}$, eds. Epidemiology of sports injuries. Champaign, IL: Human Kinetics, 1996;3:29-40.

17 Johnson RJ, Ettinger CF, Shealy JE. Skier injury trends: 1972-1990. In: Johnson RJ, Mote Jr CD, Zelcer J, eds. Skiing trauma and safety: ninth international symposium. Philadelphia: American Society for Testing and Materials, 1993:11-22.

18 Bouter LM, Knipschild PG. Causes and prevention of injury in downhill skiing. Physician and Sportsmedicine 1989;17:81-94.

19 Shealy JE. Comparison of downhill ski injury patterns: $1978-81$ vs. $1988-90$. In: Johnson RJ, Mote Jr CD, Zelcer J, eds. Skiing trauma and safety: ninth international symposium. Philadelphia: American Society for Testing and symposium. Philadelphia: A

20 Ekeland A, Holtmoen $\AA$, Lystad H. Skiing injuries in alpine recreational skiers. In: Johnson RJ, Mote Jr CD, Binet M, eds. Skiing trauma and safety: seventh international symposium. Philadelphia: American Society for Testing and Materials, 1989:41-50.

21 Lystad H. A five-year survey of skiing injuries in Hemsedal, Norway. In: Johnson RJ, Mote Jr CD, Binet M, eds. Skiing trauma and safety: seventh international symposium. Philadelphia: American Society for Testing and Materials, 1989:32-40.

22 Lamont MK. New Zealand ski injury statistics: 1989 and 1990 ski seasons. In: Johnson RJ, Mote Jr CD, Zelcer J, eds. Skiing trauma and safety: ninth international symposium. Philadelphia: American Society for Testing and Materials, 1993:33-42.

23 Ljung B, Bauer M, Edlund G. Severe ski injuries: the decision is the responsibility of the skier. Läkartidningen 1991; 88:1583-6. (In Swedish.)

24 Ekeland A, Røed Larsen S, Tuxen AG, et al. Organization of skiing safety in Norway. In: Johnson RJ, Mote Jr CD, Binet $M$, eds. Skiing trauma and safety: seventh international symposium. Philadelphia: American Society for Testing and Materials, 1989:342-53. 


\section{Commentary}

The strength of this study is the very large number of skiing injuries analysed and its longitudinal design in which the injury distribution among three popular types of skiing and snowboarding during a six year period is reported. The weakness is the lack of any control material which would allow risk calculations for different ages, skiing abilities, and skiing experience. The latter is, however, not easy to acquire for a multicentre study running over a six year period. The paper reports a very high proportion of fractures among the injured skiers in contrast with many other reports. The authors could have pinpointed more clearly in the discussion that this is probably due to the fact that only the most severe injuries are reported (only those treated in hospital or hospital emergency departments), whereas many other papers also include injuries treated by the local physician at the ski resort or even ski patrol reported injuries. It is also probable that the injury incidence associated with a specific skiing activity is more representative of increasing or decreasing popularity of this activity (change in exposure time) than changes in the risk of this type of skiing during the period studied. ${ }^{1}$ A significant finding is the increasing proportion of snowboarders in the injured population. The authors state that this is probably because of the large number of beginners in this sport, in agreement with other studies. Shealy ${ }^{2}$ has reported that the injury risk for snowboarding is about the same as for alpine skiing when controls are made for skiing and snowboarding ability. ${ }^{2}$

The large number of skiing injuries reported give valuable and updated information about the injury distribution in the most popular types of skiing activity and also constitute a valuable basis for planning of future studies, which should be case control studies allowing investigation of injury risk and causes.

ARNE EKELAND

Martina Hansens Hospital, N-1355 Barum, Norway

1 Johnson RJ, Ettlinger CF, Shealy JE. Skier injury trends: 1972 to 1994. In: Johnson RJ, Mote Jr CD, Ekeland A, eds. Skiing trauma and safety: eleventh international symposium. Philadelphia: American Society for Testing and Materials, 1997:37-48. 2 Shealy JE. Snowboard vs. downhill skiing injuries. In: Johnson RJ, Mote Jr CD, Zelcer J, eds. Skiing trauma and safety: ninth international symposium. Philadelphia: American Society for Testing and Materials, 1993:241-54.

\section{B Fry: not quite a true genius}

Samuel Johnson maintained that "The true genius is a mind of large general powers, accidentally determined to some particular direction". This is perhaps one of the reasons why the brilliant all round sportsman and academic C B Fry never quite achieved true genius.

Charles Burgess Fry was unquestionably the greatest sportsman of his generation-some say of all time. If Blues in cricket, athletics, and soccer were not enough, he also equalled the world long jump record while at Oxford and later went on to play football for England, win a Cup Final medal and captain England in 1912 in the only triangular test match series against Australia and South Africa. But his talents were not limited to sporting brilliance. He was a Greek scholar, author of several books, editor of magazines, delegate at the League of Nations, politician, and for more than 40 years Captain Superintendent of the Training Ship Mercury. It was also rumoured that he had been offered the throne of Albania!
If the sheer breadth of his talents was one obstacle to his achieving true genius, illness, which was to dog his later years, was the other. As a young man he had episodes of depression, and, while at Oxford, Maurice Bowra described him as living on "a manic curve". In 1929 when travelling in India with his friend Prince Rajitsinghii, he became ill with paranoid symptoms and bizarre behaviour. On returning home he was withdrawn and unable to communicate, remaining ill for several years. In later years he was difficult, impulsive, and monopolised conversation with a constant flow of odd ideas and bizarre topics. With hindsight a bipolar affective disorder seems the likely diagnosis.

A brilliant talent, but genius-not quite.

A fuller version of this article will appear in the fournal of Medical Biography.

P J TOGHILL

Director of Continuing Medical Education 